\title{
NONVERBAL COMMUNICATION IN THE CONTEXT OF DISSOCIATIVE PROCESSES
}

\author{
Thomas G. Arizmendi, PhD \\ Roseville, California
}

\begin{abstract}
Nonverbal communication, at both conscious and unconscious levels, can be portrayed as a type of "body language," a communication between the psychic bodies of patient and therapist. In this article, the author provides several examples of this communication process in the context of a psychoanalytic treatment with a patient who has a history of trauma resulting in frequent dissociative states. Motoric actions (drawing), somatosensory symptoms, and intense affect states represent the media through which she "informs" the analyst of her painful experiences. The analyst's surrender to countertransference states, such as deadness, constitutes the beginning of attunement to the patient's body communications. In one particularly unusual symptom of dissociation, the patient exhibits physical abilities that she is incapable of in more integrated states. An attempt is made to understand this event from a phenomenological and neurobiological perspective. Using an information-processing model, the author illustrates one instance of how the patient's subsymbolic information may be converted to the verbal symbolic via the analyst's use of evoked images.
\end{abstract}

Keyword: nonverbal communication

Filthy fingers forging further, Debris sinking into a once pure soul, An ignorant man in numerous ways, Yields more power than deserved, As he scavenges her, Peacefully asleep a child lay one night. . Mind reeling, Seeking for passages of escape... Physically he is gone, But mentally he is still with her. . Now even more dejected does this little girl feel, Alone with her turmoil, In an unsafe place. . (italics added) -Survivor of Childhood Sexual Abuse

In response to trauma, dissociation has been described as providing "the escape when there is no escape!" (Putnam, 1992). Excerpts from a poem written by a young college student (above) illustrate the extremely painful and overwhelming effect of a horrific event that results in a kind of "soul murder" (Shengold, 1989) and refer to the escape often provided by dissociative processes. Under the intense circumstances of trauma such as the sexual abuse of a child, the psyche is overwhelmed and cannot process in normal,

Thomas G. Arizmendi, PhD, independent practice, Roseville, California.

Correspondence concerning this article should be addressed to Thomas G. Arizmendi, PhD, 729

Sunrise Avenue, Suite 614, Roseville, California 95661. E-mail: thomasariz@quiknet.com 
reflective fashion because of the threat of annihilation. In these instances, which represent the primary context for my discussion, dissociation leads to a disconnection between the actual event and its symbolic (verbal) representation (Davies \& Frawley, 1994). Thus, dissociated experiences are not symbolized and not communicable by ordinary language. When depicted as a "healthy adaptive function" (Bromberg, 1996), dissociation allows, paradoxically, for the intactness and coherence of one's self. Under extreme conditions such as those associated with trauma, however, it can evolve from a normal process into a defense in which the person becomes "not me." In the case of recurring trauma, dissociation constitutes an "early warning system" (Bromberg, 2003b), alerting the person to the threat of impending catastrophe and it is essential to the formation and maintenance of separate self states.

In the analytic relationship, patients who rely heavily on dissociative processes often "communicate" via sensory experiences, using their psychic body to inform and, simultaneously, to regulate the analyst via these sensory messages. The therapist, in turn, communicates via a type of "body language" as well, receiving the patient's nonverbal communications through the messages she (therapist) receives from her own psychic body.

In what follows, I will attempt to illustrate subsymbolic, nonverbal (sensory, visceral, and motoric) body communication through the use of extensive clinical material from an ongoing psychoanalytic treatment involving trauma. The focus will be on the idea that the patient attempts to communicate via body experiences and that the therapist receives them via his own body experiences. Furthermore, I will outline, using a model from cognitive science, one idea as to how these nonverbal, subsymbolic forms of body signals may be converted to the symbolic mode within the medium of the patient-therapist interactive process.

\section{Unconscious Communication: A Brief Review}

Remarkably, even before Freud, Charles Darwin gave detailed accounts of unconscious, nonverbal expressions in both man and other animals (see Pally, 2001). He turned the lens toward neuroscience, at this early time, by suggesting the connection between affective communication and the activity of the nervous system. Following Darwin, researchers have studied and demonstrated how animals emit nonverbal behaviors as a primary form of communication and these are often designed to trigger nonverbal responses from others. For example, attempts to trigger such states as fear or to signal a state of sexual readiness via behavioral or sensory expressions have been well documented for decades.

In psychoanalysis, we generally attribute the first major focus on unconscious communication to Freud. In one of his most famous papers on technique, he outlined the analyst's counterpart to the patient's role of free association; he instructed the analyst to orient his unconscious mind toward that of the patient, using it as a type of "receptive organ" (Freud, 1912). A few years later he hinted at the notion of "body language" more directly when he referred to sensations as "organ speech" (Freud, 1915, p. 199). What we sometimes overlook, though, is that while Freud's change to the free association technique paved the way for him to subsequently introduce the general notion of unconscious communication between patient and analyst, at the same time it constituted an early detour away from the potential focus on dissociative processes. Influenced by Cartesian dualism and his desire to promote psychoanalysis as a legitimate science, he actually encouraged 
a mind-body split when he abandoned the method of hypnotic touch in favor of free association during his early work with hysterics, placing the emphasis on the mind while de-emphasizing body experience (Looker, 1998; Wrye, 1998).

Despite this overemphasis on the mind, Freud's initial comments on the analyst's stance did indeed pave the way for future clinical observations. Klein (1946) introduced the notion of "projective identification" and, subsequently, the projective-introjective model has become widely used to explain the unconscious communication of unwanted, painful affects and sensations. Reik (1948) and many others have attempted to illustrate how these processes are essential for the analyst to understand the patient's experience. They broadened the focus by emphasizing the patient's nonverbal communication (e.g., sensory cues, body movements, speech variation, etc.) both in the conscious and unconscious spheres. The template for these notions of Klein, Reik, and others was not only provided by Freud but perhaps even more specifically by Ferenczi. In his diary entry of January 17, 1932 (Dupont, 1995), he introduced the notion of "flowing over," a "mutual flux." This represents a "metaphysical," preverbal connection between the two participants occurring in mutual analysis. He further argued that this process of exchange was due to differing levels of tension between the two people. The notion of flowing over was accepted as a legitimate form of unconscious communication for not only love and other emotions but also for sensorial substances such as heat and odor (Hermann and Bak in Hidas, 1993). It was understood as a precursor to projection, a type of "osmotic communication" that can be first observed between mother and child. The effects of these nonverbal, primitive communications have proven to be substantial for the analyst, often leading to physical discomfort and an impairment of his ability to concentrate (Rosenfeld, 1987).

On the basis of more contemporary findings, we understand that unconscious, nonverbal communication is clearly present from birth and there is mounting evidence that it exists even during the gestation period. The mother-child attachment process is highly dependent on sensory, visceral, and motoric "language" (see Pally, 2001 for a review). Mother and child can locate one another from the start primarily via smell and touch (e.g., the smell of mother's breast milk, skin contact, etc.). Furthermore, as development continues, the emergence of symbolic, verbal language, while a huge milestone, also represents a paradoxical achievement. It both expands and limits the child's ability to express his internal world to another. Stern (1985) and others have explained that conventional language is inadequate to communicate experience and inevitably creates a gap between the inner personal world and the external world that relies on the traditions of accepted labels and concepts. Within the last two decades, infant researchers, focusing on the facial expressions, gestures, voice rhythms, and prosody of mother/infant pairs, have emphasized procedural implicit processes, automatic actions (see Beebe, Knoblauch, Rustin, \& Sorter, 2005 for a review). Implicit communication is not only a constant, ongoing process in any dyad but can provide information about one another without explicit acknowledgment ever occurring. This has been referred to as "implicit relational knowing," a critical noninterpretive mechanism of the change process that relies on the enactive or "how to do" as opposed to words or images (Lyons-Ruth, 1998; Stern et al., 1998).

One of the domains in which implicit processes have been extremely beneficial and that constitutes the major context of this paper is in the development of models explaining the effects of early trauma on subsequent childhood and adult life. Schore's (1994, 2002, 2004) research tells us that the right hemisphere, dominant for implicit processes, is the locale for the imprinting of early trauma (autobiographical memory) that often leads to a 
compromised ability in the child to regulate the intensity and duration of affect. Childhood abuse can have specific neurobiological sequelae including the inability of the right prefrontal cortex to regulate amygdala functions (such as the processing of frightening faces). These consequences result in what we later see in adults as critical symptoms of posttraumatic stress disorder - the vulnerability to states of hyperarousal often triggering dissociative states.

Among other areas of research, neuroscientists have been focused on nonverbal, implicit communications and how gestures or actions can represent an early, presymbolic form of language. The discovery of mirror neurons has been the foundational centerpiece in this effort (Gallese, Fadiga, Fogassi, \& Rizzolatti, 1996). These neurons are cross modal, meaning they are activated both when observing or performing a specific action. Gallese (2003) has described an empathic, intersubjective communication process that is completely implicit and automatic, relying on prereflexive action simulation (at the neurological level) that connects the observed with the observer. In brief, neuroscientists are finding that the process of observing another's actions (e.g., body posture, facial expressions, speech, etc.) creates a simulated experiential state in the body of the observer (embodied simulation) via the work of mirror neurons. In essence, our states of empathic attunement are grounded in our body experiences and this happens automatically, without conscious effort beyond that of listening and observing (Carr, Iacoboni, Dubeau, Mazziotta, \& Lenzi, 2003; Gallese, 2001, 2003; Wolf, Gale, Shane, \& Shane, 2001).

What are still very much unaccounted for are the various meanings each participant assigns to his or her body experiences that are influenced by the individual's unique associational and narrative history. Understanding the mechanism as to how this occurs on a neurobiological level would, I believe, form a vital bridge to psychoanalysis and virtually all clinical work. Nevertheless, neuroscientists, infant researchers, and psychoanalysts, now working in concert, have created a rich cross-fertilization process. In what may eventually become the substance for a multidisciplinary framework of change, they are currently accumulating data with regard to implicit nonverbal communication, explaining its origins at the neural level and how this becomes transformed at the level of the mind.

\section{Communication Through Body Memories and Dissociated Actions}

Cathy, a depressed single woman in her mid-30s, entered treatment declaring that it was a chosen alternative to suicide. As I learned later in our work, it was the voice of the dissociated self who felt she was dying and who was desperately seeking a safe environment where she could become known. Throughout much of the first 2 years of therapy, the patient frequently sat in a slumped posture with her long hair concealing her face. She often echoed, in an accepting manner, the self-loathing words of her alcoholic father who emotionally and verbally abused her for years beginning in early childhood. Experiences of helplessness and aloneness accompanied, at times, by a pervasive sense of deadness consumed me as one attempt after another to reach her through interpretations were experienced as meaningless and irrelevant. At times, Cathy would "fade away" into a dissociative state, triggering my own form of paralyzed retreat.

The ambience of deadness and paralysis (Ogden, 1995), quite common in work with traumatized patients who exhibit dissociative states (Bromberg, 1998; Davies \& Frawley, 1994; Goldberg, 1995; Levine, 1990; Lisman-Pieczanski, 1990), could be interpreted as a form of mutual retreat by the patient and therapist, building their own protective cocoons 
in a sense (Goldberg, 1995). However, my sense was that something much more active was present. There was a type of nonverbal communication evolving that constituted a significant part of our work. The sensations of deadness, paralysis, and helplessness likely represented some attempt, on the part of the patient, to describe dissociated states she experienced during the painful traumatic episodes of childhood (Levine, 1990). In particular, on several occasions the patient, who has experienced many symptoms suggestive of sexual trauma (e.g., body memories in the inner thigh and genital areas, nightmares, intrusive sexual thoughts and fears, etc.), recovered fragments of memories in which father would enter her bedroom late at night. She would immediately collapse into a lifeless-like posture while holding her breath. The patient recalled an overwhelming sense of helplessness, deadness, and disorientation that was quite similar to those I experienced in the treatment. Using the findings from neuroscience articulated above, I would understand my experiences of deadness and paralysis as examples of communications from the patient (representing a dissociated state), in the here-and-now transference relationship, received by me through the process of embodied simulation. That is, my observation of the patient's actions, including her expressions of affect, led to a mirroring (mirror neurons) of her actions/experiences in me. ${ }^{1}$

Turning back to the clinical material, Cathy has had a history of difficulties with bowel movements dating back to early childhood. She described the painful scenes in which her parents would forcefully administer an oral laxative to relax her state of constipation. As she began to experience an increasing sense of safety in the therapy, the patient revealed a lifelong sensation that her anus was "ripping." The sensation itself or the anticipatory fear of it continues to result in anxiety whenever she has a bowel movement. She often tries to avoid the bathroom whenever possible. Drawing was a frequent means of communication for Cathy and, in one particular hour, she described this "ripping" while drawing a figure that had a series of jagged edges protruding in concentric fashion. As I listened, I winced as if a sharp protruding object had pierced me and began having images of a circular saw ripping through an object and of someone ripping two objects apart. The pain I experienced was intense and I was only able to recover while viewing a second picture of what looked like a more intact circle without the jagged edges. In my attempt to avoid further pain, I compared the two circles and told her that "it looks to me as if things are getting better." She, of course, ignored my comment and continued to draw pictures, this time of a long "bamboo stick" (patient's association) as well as two eyes and an L-shaped tube. Unwittingly, I needed to ignore these objects and remain in my state of hope that things were better and that the treatment was progressing; another instance of my dissociating for the purpose of disconnecting affect from the visual "evidence" and the potentially painful body experiences that might accompany it. However, during the next few months, the patient became increasingly fearful that she had been sexually abused and that some of these drawn figures had distinct meanings related to possible abuse. For example, the L-shaped object was recognized by her as the faucet of her bathtub that

\footnotetext{
${ }^{1}$ In my opinion, embodied simulation, as an intersubjective reciprocal process, represents a more general, biologically grounded theory of unconscious affective communication than does the notion of projective identification and the associated idea of therapist as container (Bion, 1962). The latter is used to describe an unconscious evacuation process of the patient's unwanted affects whereas embodied simulation is not context-specific. Perhaps, as Modell (2003) suggests, the research on mirror neurons will help to deconstruct the mystery of how projective identification actually works and, more broadly, provide some explanations for an unconscious communication scheme in psychoanalysis and in interpersonal relationships as a whole.
} 
threatened to touch her backside if she did not watch it carefully whenever bathing. In a hypervigilant manner, she would check and recheck her position with regard to this "menacing" object.

Body memories are a common form of dissociation often providing a window into the original traumatizing event (Davies \& Frawley, 1994). They represent a somatic, unsymbolized form of communication that, I believe, is often received somatically by the therapist. As I first tuned into Cathy's pictures on a cognitive level, my efforts to "see" what she was communicating led me to make feeble, ineffective attempts to make sense of her pictures. Cathy, in her own sensory cocoon of "rippedness," was disconnected and protected from me and any of my attempts to integrate or begin to symbolize her sensorial experience. What her body communicated to me was a specific sensation of intense, sharp pain. At that point, that was all her psyche could tolerate but it was all that was needed once I surrendered to my own body signals. Most critical was the sense of being overwhelmed which was, I believe, her communicated memory of being overwhelmed herself. I recognized this by the intensity of my pain and the urgent need to "make it better" for me not just for her. I felt helpless and needed to find a means to escape and to provide hope where it seemed as though none existed. Over the course of treatment, similar experiences of intense pain, fear of overwhelm, confusion, and helplessness have colored our atmosphere as the patient expressed other body memories such as piercing pain ("like knives") on both sides of her head, a sensation of pressure on both knees upon awakening as if being held down in her bed, and the sense of "hot fire" in her stomach.

In addition to body memories, there are numerous symptoms that are typical of dissociation. What is not typical, though, is the manifestation of physical or mental abilities contained within a dissociated state that are otherwise nonexistent (Stern, personal communication, June 6, 2003). This occurred in my work with Cathy. On occasion, when in a dissociated child self-state, she would draw with her left hand. The drawings were consistently erratic and quite primitive-similar to those produced by a toddler. She recounted how this left-handed drawing happened numerous times at home and, although she had no memory of the actual switching to her left hand, she knew retrospectively that this meant it was "her" who was now drawing. In one particular instance, she began to stare out the window and I could feel her drifting as she became aware of painful memories involving humiliation. She switched the pen to her left hand whereupon I lost verbal communication with her. Instinctively I focused on her left hand and, to my astonishment, she drew in a smooth, coordinated and confident fashion. Her movements were every bit as mature and natural as those I was used to seeing with her dominant hand and she was careful to fill in details, punctuate certain areas, and so on. In a quiet child's voice she proclaimed "See, it's a bed, one of those with four posts!" The picture was as articulate as anything she had done with her right hand. I sat in shock for a moment and then lapsed into a state of confusion and disorientation. Was she left-handed and I simply had not noticed? Perhaps she was ambidextrous. With each passing moment I became less sure of myself. How could I be unsure of this after all these years of treatment and after having seen her draw many times before? What was real and what had I just imagined? Over the next several days (including a consultation session), my fog cleared and I realized that this had been an extraordinary event. In the next session the patient complained of feeling extremely tired after the previous hour. When I asked for her memory of it, she could only reiterate themes that we had discussed before the dissociative episode. We looked at the pictures she had drawn and I inquired as to whether she recalled drawing it. She offered a firm "No" and when I informed her that she had drawn it with 
her left hand she vigorously shook her head and chuckled, adamantly insisting that she could have never done that with her left hand!

Despite the fact that this is a rather unusual dissociative phenomenon and probably escapes explanation on a physiological level, it seemed to be conveying a rather important affective message. Cathy's behavior had triggered (communicated) a sense of shock, self-disparagement, overwhelm, and self-doubt in me. Most importantly, her actions (drawing) communicated confusion between the real and the imagined-a common and often chronic experience suffered by many abuse victims. I had experienced a temporary mistrust of my faculties and my ability to use historical knowledge to validate my sense that this had been an unexplainable event. Concurrent with the recognition of these thoughts, I began to understand that she was communicating the ineffable, that which was not thought and that which she could not articulate in any other way yet, in some way, she "knew"-the unthought known (Bollas, 1987). Presently, several months later as I write this, I notice seedlings of doubt taking their grip. Am I portraying this accurately? Was she really that smooth and articulate in her process? If this confusion exists in me after a period of months, how could I even begin to comprehend the confusion this patient feels after more than 30 years amid numerous vicissitudes of doubt and uncertainty that have emerged in her?

\section{The Evolution of "Knowing": From the Subsymbolic to the Symbolic}

One of the major challenges in working with dissociative patients is that of transforming that which is received from implicit to explicit knowing. The task of both participants, but primarily the therapist, is to pay attention to the received body "message" transmitted by the patient via the intersubjective matrix that is constructed between the two. Often, although not always, it is therapeutic for this implicit knowledge to be made "community property" (if possible)-that which can be articulated and understood by the patient as well as the therapist and is then available for negotiation, clarification, and interpretation. The transition is from the nonverbal body knowledge (conscious or unconscious) to the verbal symbolic (i.e., language). But how do we do this?

Cognitive science offers a model that helps explain the process of transforming the subsymbolic to the symbolic. Multiple code theory (Bucci, 1997, 2001, 2003) provides a "psychoanalysis friendly" derivative of the standard theories of information processing in that it takes into account not only cognitive processing but that of emotions as well. In this theory, information processing is conceptualized as occurring along one of three modes: the subsymbolic (nonverbal), the symbolic nonverbal, and the symbolic verbal (this mode is what differentiates humans from other animals). Symbols have the characteristics of being discrete, of referring to something else, and of being generative. They may be words or images. The subsymbolic, by contrast, refers to that which varies along continuous dimensions-it is "analogic and holistic" (Bucci, 2001). However, the subsymbolic mode must not be conflated with the standard notion of the unconscious; all three processing modes may occur at the conscious or unconscious level. The linking of the nonsymbolic and symbolic modes occurs via the symbolic nonverbal mode that refers to images. Images are the key referents connecting the subsymbolic nonverbal affective cues (e.g., sensory information, motoric action, etc.) to words that can be used in treatment. Emotions may be communicated, for example, in verbal form using images, stories, metaphors, and so forth that can be shared and identified with by another and may even evoke a similar experience in the other. 
The three principal modes of information processing are the primary players in the transition from implicit to explicit knowing. This transition process is referred to as the "circle of emotional communication" that Bucci (2003) describes in the following way:

"The patient is communicating to the analyst, in multiple subsymbolic channels, aspects of the emotion schema that have been aroused. The patient's communication activates subsymbolic experience in the listening analyst and activates a schema composed of the analyst's experience of the patient and of the analyst's own life..."

"The transformation from knowing in the bodily, sensory, motoric sense to knowing in the symbolic mode-first images, then words-occurs within the analyst's inner experience, in the context of the analyst's own emotion schemas, before "emotional inference" to the patient's experience is made. The analyst then uses his own subsymbolic experience, imagery, and ideas as information concerning the patient's state" (p. 553).

The circle of communication described here provides an explanation of how information transfers from the body of one participant to the body of another and then, via imagery, can be translated into the symbolic verbal mode of words. Of course, there can be body- to-body communication that does not evolve into words but nonetheless results in motoric, sensory or verbal interactions between participants. For example, in the case of one patient, both of us experience long periods of anxious confusion-where we have difficulty thinking beyond a concrete level and where the patient's only verbalizations are often inarticulate utterances. Yet the body tension is unmistakable for both of us and clearly, something is being communicated from body-to-body but cannot be grasped in symbolic form.

Once again, I would like to use a vignette from my work with Cathy to illustrate how Bucci's model can explain the process of ideas and emotions transferring from the subsymbolic (body) to the symbolic verbal. The following is an excerpt from a session in which the patient had communicated how she was being kinder to her little girl after the last session and had noticed that, recently, she had been more sympathetic and compassionate to her than in the past. While talking she was also drawing and I began to inquire as to the nature of her picture.

$\mathrm{T}$ : What are you drawing?

P: . . . boxes, squares, rectangles — the thing about drawing with pen is you can't make it go away ... it looks like a big rug ... somehow I cut off the corner (see Figure 1).

P: I don't understand. I can't figure out why it's. . .I can't figure it out (now with a soft childlike voice)-why don't they meet?

I felt confusion because it seemed obvious that she had drawn them at the wrong angles. I was still operating on a very concrete adult level and I tried to explain the problem but she did not respond. We were not in full contact with each other, once again.

P: I need a little more paper over here. It's not the same (whispering). I want to fix it-I don't like it-it's not perfect. (she seemed irritated)

T: Just like she didn't like it either (the patient seems to be ignoring my comment)

P: I don't get it. (looking down at the drawing and the lines that do not meet.)

T: She had horrible images and you wanted to fix it-you still do. (I respond as if she was confused by my last statement and not the drawing.)

The patient continued to stare at the paper. I experienced continued loss of connection with her and remained perplexed as to why she could not and would not fix the drawing. This constituted my own dissociated state where my comments were more for my own benefit. I was immersed in a countertransference analogue, the withdrawn response to my 


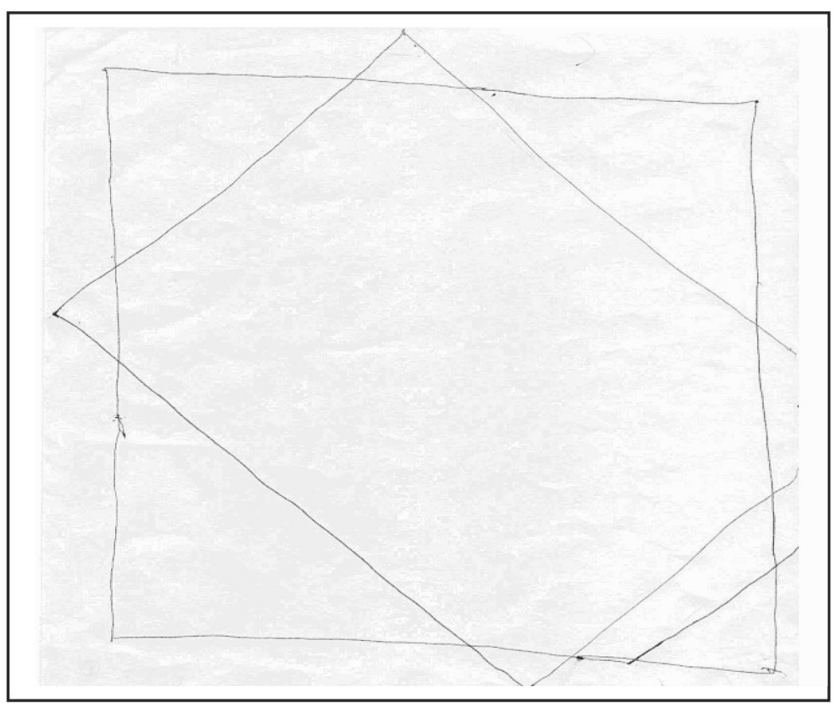

Figure 1. Drawing before the "disaster" interpretation.

patient's withdrawal. I had dissociated and tried to reconnect with her but then lapsed into silence with a sense of resignation. Gradually I surrendered to a sense of gloominess washing over the room followed by an identifiable sense of doom. As I began to reflect on this experience in my body, I had the image of two live electrical wires touching and creating a jolt in me. With regard to her drawing, I said the following:

T: Maybe you don't have them meet because that's where the disaster is!

Cathy immediately pulled out a clean piece of paper, held her pen inside a fist and began to draw chaotic lines with extremely heavy pressure (see Figure 2).

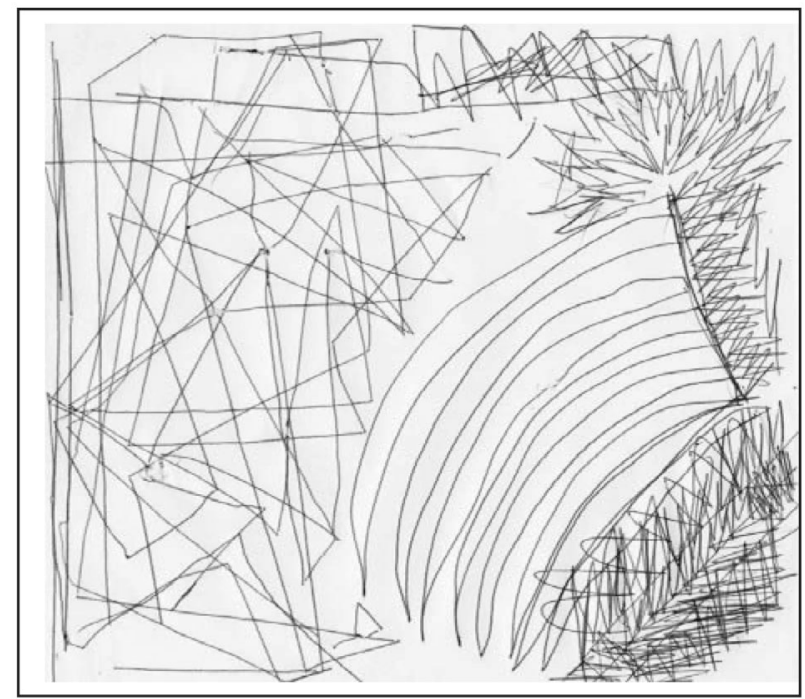

Figure 2. Drawing immediately after the "disaster" interpretation. 
T: What are you drawing?

P: (child's voice) I don't know-fingers, pointy fingers.

She began to punch holes through the paper with her pen where the lines intersected. The "pointy fingers" stemmed from a figure that, in previous drawings, she had identified as a vagina (although she had never been able to say this word). Note that the patient now seemed to be in direct contact with me, unlike her previous state.

T: What's going on?

Moments later, the patient stuck the pen through and began to rotate the paper while holding the pen still.

P: It says "don't move-I'll do it-stay still - I'll do it"

T: Who is saying that?

P: I don't know-somebody. . .It's a "he."

In the next hour, Cathy did not recall any of this but did recall feeling exhausted after the session. In the following hours, she seemed to form a stronger bridge (Pizer, 1998) with her child self-state. She acknowledged her awareness that there were other parts of her (the child) that were not so playful and spontaneous. This acknowledgment was a new event in our work. Cathy took an empathic stance toward the child, telling her that both she and "Dr. A." would be patient and wait until she was able to bring this other part of her into the room. Despite this shift and other signs of progress, Cathy has once again experienced the headaches and stomach aches that had subsided for awhile and she attributes this to her contact with that part of her child that contains the "bad" feelings. She both wants to hold her off but also realizes this child must have a chance to express herself and feels her forcefully pressing to enter the room with us.

Before analyzing this interaction within the framework of Bucci's model, a few comments are necessary. While Cathy was in a brief dissociated state and was possibly reliving some version of a past traumatic event, she was able to emerge from this state and we proceeded to live on the "edge." In other words, the unanticipated, uncontainable shock became barely containable over the remainder of the hour and during the ensuing weeks of treatment (Bromberg, 2003b). She had experienced intense fear but now in a safer environment. This allowed her to acknowledge, for the first time, that there was another part of her child that she had never recognized, a self-state (persona) consisting of the anger and rage-the "fire in my stomach" that she had previously described but without the ability to identify a specific emotion. Before, it was simply a raw sensation. Now she could label it and had some idea of its affective meaning but it was still too threatening to be part of a complete "me." However, there clearly was an emerging connection to this angry child state (Pizer, 1998).

In the past few months, Cathy has moved toward this fiery anger and has been able, in the context of our relationship, to regulate its intensity to some degree. At one point, we were able to diffuse it just as she felt herself beginning to "slip away." She recognized the danger associated with this "fire" and realized she was not equipped to confront it except in small doses. In another context, however, she has revisited memories of previous sexual experiences as an adolescent and young adult but now in a new way. Her history of impulsive sexual liaisons with men has subsequently resulted in deep regret and intense feelings of shame. The patient was also the victim of a rape at the hands of an ex-boyfriend. In the past, she would describe these experiences in a numb, dissociated fashion, as if they had happened to someone else, disclaiming emphatically, "that was not me!" More recently, however, she revisited a particular sexual incident but this time with full recognition that it was she who experienced this and while she expressed anger and disgust for the man, she also acknowledged shame in herself as a willing participant. Not 
only was dissociation absent but it had been replaced by a resolute boldness as if to say, "here I am, all of me and I know I will survive." She has also been able to spontaneously describe sexual thoughts that carry shame and has even whispered the word "vagina." The patient is now less restrictive toward me and has created more space for us to exist and mutually regulate in the sphere of sexual conversation. As this has occurred, I have become more comfortable discussing sexual ideas in the treatment process while still maintaining a certain degree of caution because of the strong possibility for enactment in this context. In general, though, there is less aversion to these and related issues for both of us. Despite the fact that the sexual traumas occurring in adolescence and adulthood do not constitute the original traumas, they do represent overwhelming events in which she is now able to represent herself as the subject and can both feel, express and tolerate the anger and shame that accompany them. This is a critical step toward the eventual symbolization of experience (LeDoux as cited in Bromberg, 2003b). Furthermore, it has been noted (Bromberg, 2003a) that the successful treatment of traumatized, dissociative patients does not necessarily require the recovery, in symbolized form, of the original event.

In terms of therapeutic action, how might we understand what happened in this exchange that contributed to the patient's progress? Returning to multiple coding notions will provide some helpful ideas. Cathy's drawing process is a form of subsymbolic nonverbal (motoric) communication. Her comments about the drawings and the process suggest this represents a conscious process. The patient, in a dissociated, altered state, expressed confusion and irritation (subsymbolic), for example, when she could not figure out why the lines did not meet. I was also immersed in confusion. My initial attempt to explain the problem on a concrete, practical level was likely a sign of a brief dissociated state, as I mentioned above. According to the circle of communication concept, Cathy was communicating with me along multiple subsymbolic modes (motoric and affective) and she had activated subsymbolic experiences in me (e.g., confusion followed by withdrawal in the form of a dissociated state). I was locked into an explanation that was completely disconnected from Cathy's altered state as manifested by her failure to "hear" me and to respond on this concrete level. I then had a second subsymbolic experience of gloominess that was activated by the patient's behaviors and the intersubjective realm we constructed. This affective experience triggered an image (the symbolic nonverbal referential link) of two wires touching one another and jolting me. The transition from the subsymbolic (confusion followed by gloominess) to the symbolic nonverbal occurred within my subjectivity and then led to the symbolic verbal statement regarding "disaster." The ensuing dialogue and drawing (see Figure 2) indicated, I believe, that I was now in touch with a communication from her body to mine-a chaotic sense of disaster. Although the patient remained on the subsymbolic level of motoric action (i.e., drawing), she was conscious not only of this process but also of some specific part of a possible traumatic experience-a sense of penetration regarding the female genitalia. The drawing likely represented a chaotic experience that now existed between us. However, she could not convert the process and content of the drawing to a symbolic verbal mode. The patient did have the images of pointy fingers but they were not sufficiently linked to other images, at this point, to aid in the articulation of a story. Nevertheless, the transformation in me from subsymbolic to symbolic verbal and my communication back to her seemed to resonate with an affective state in her and ostensibly to transport her closer to important images which she either could not bear to communicate or just could not bring to awareness at that moment. In fact, upon closer examination, Cathy did have at least three images that were likely connected to one another; pointy fingers, something she had previously identified as 
a "female part," and a third more ambiguous image of a "he" who spoke in a demanding manner. To be more precise, where she was blocked (in the conscious realm) was in her ability to "know" or perhaps to articulate just what the relationships were between each image. This may suggest that other images were still unavailable and that the story as to how they fit together remained sequestered in another dissociated state(s). In a sense, the images, like the lines in the drawing, could not be connected because of the disaster of knowing, on a verbal conscious level, what had happened to her as a child. From my perspective, her inability to connect the images and the lines signaled that she was not emotionally prepared to know, at that moment in time and that even approaching this triggered a sense of chaos in her (see Figure 2).

Although we have been able to shed some light on the deconstruction and explanation of the therapeutic process in the above vignette, there remains the task of trying to explain the "unexplainable." Cathy's drawing with her nondominant hand, described earlier, represents an anomaly that stretches beyond psychoanalytic measures we have available at the current time. How could she have suddenly become ambidextrous for this one episode? On a physical level, this is clearly an enigma to say the least. Based on recent fMRI data, we have become increasingly confident that emotional pain is expressed neurologically via activity in the right hemisphere (Schore, 2004). Therefore, it would make sense that her left hand would be the architect for the communication of the pain associated with traumatic experiences. The point is that if we conceptualize the left hand activity as the conveyor of her emotional pain and that she is the expert, in this regard, then the patient's sudden new ability makes perfect sense and should not come as a surprise. On a strictly physical/biological basis, however, we still cannot explain the underlying mechanisms for this extraordinary event and, to my knowledge, the current literature does not provide definitive answers.

On a phenomenological basis, we do have some ideas that provide a somewhat plausible explanation for understanding the patient's unpredictable left-handed performance. Because he was so captured by the effects of trauma on the human psyche, Ferenczi developed a theory in which he suggested that part of the self, under the shock of traumatic experiences, splits off from the rest and becomes a mature, maternal helpful self (altered state) that acts to protect the damaged self (Ferenczi, 1931). He used the medical metaphor of "teratoma" (tumor) to describe that part of the personality that was damaged by the trauma, leaving another part that has been spared and can assume the task of adapting to reality-essentially acting as a parent to the traumatized child. Cathy's dissociated self-state that was responsible for the mature and accurate left-handed drawing would be evidence for Ferenczi of the split off wise self that has mature, adult-like qualities. His idea was that patients, under the weight of overwhelming stress, may succumb to a kind of hallucinatory process in which parts of the body are either newly formed or newly empowered on an imaginative level and can perform the function of otherwise exhausted organs (Dupont, 1995). He continues by saying that such "new organs" are formed not in a gradual manner but very rapidly. Perhaps he was trying to convey a type of reparative or restorative process, a certain counterbalance and yet a parallel process to the notion of hysterical displacement (e.g., temporary paralysis, blindness, etc.). Although his ideas certainly involve some unexplained gaps, Ferenczi's notion of the imaginative, hallucinatory process activated by the shock of traumatic events may translate to body performance that was, in his era, impossible to explain on a biological basis. In the dissociated state of a little girl persona, Cathy may have "hallucinated" her physical body into an extraordinary event with the help of a "new organ." An important area of inquiry would seem to be an explanation of the extent to which the 
hallucinatory power of an altered state reflects newly formed neural networks that activate body functions. Such an investigation becomes more attractive when we consider that the cortex maintains a significant degree of plasticity throughout life resulting in the fact that, at any period, experiences can modify our neurobiological map and our functioning as well (Perry, 1999). Furthermore, contemporary research in the area of neuroplasticity is confirming the integration of imagination and action. Using transcranial magnetic stimulation, researchers have repeatedly shown in rats, monkeys, and humans that imagining an action or a physical task (e.g., piano playing) enables one to perform it as efficiently and accurately as someone who actually practiced it! The brain physically changes as we are thinking or imagining and this can be tracked (Doidge, 2007). These findings in concert with Ferenczi's notion of imagined body parts in the traumatized individual may move us one-step closer to understanding this patient's astute left-handed performance, especially because she had always imagined the dissociated child to be left-handed.

\section{Summary}

The recent elaboration in psychoanalytic theory of a multiple states model of the mind (Bromberg, 1996, 1998; Davies, 1996; Davies \& Frawley, 1994; Flax, 1996; Harris, 1996; Mitchell, 1991, 1993; Pizer, 1996, 1998; Slavin, 1996; Slavin \& Kriegman, 1992, 1998; Stern, 1997) has paved the way for a reconsideration of Janet's notion of dissociation (see Davies, 1998). The psychic overwhelm that is the kernel of trauma typically prohibits the encoding into symbolic language of parts or all of a horrific event. From one perspective, the "matter" that is constituted by the actual experience, both content and associated affects, does not simply evaporate but instead may become lodged in the body. Body memories, actions, and other cues from the sensorium provide a type of nonverbal language, unsymbolized symbols in a sense, which cannot be ignored. The patient emits signals from the sensorium that are received in the body/receptor of the therapist not as an identical reflection but as a modified one according to the influence of the therapist's subjectivity. Research in neuroscience as well as psychoanalysis and infant research are beginning to shine a wider and brighter light on some of the specific mechanisms that may account for the processes of nonverbal communication.

\section{References}

Beebe, B., Knoblauch, S., Rubin, J., \& Sorter, D. (2005). Forms of intersubjectivity in infant research and adult treatment. New York: Other Press.

Bion, W. R. (1962). Learning from experience. New York: Jason Aronson Inc.

Bollas, C. (1987). The shadow of the object. New York: Columbia University Press.

Bromberg, P. (1996). Standing in the spaces. The multiplicity of self and the psychoanalytic relationship. Contemporary Psychoanalysis, 32, 509-535.

Bromberg, P. (1998). Standing in the spaces. Hillsdale, NJ: The Analytic Press, Inc.

Bromberg, P. (2003a). One need not be a house to be haunted. On enactment, dissociation, and the dread of "not me": A case study. Psychoanalytic Dialogues, 13, 689-709.

Bromberg, P. (2003b). Something wicked this way comes. Trauma, dissociation, and conflict: The space where psychoanalysis, cognitive science, and neuroscience overlap. Psychoanalytic Psychology, 20, 558-574.

Bucci, W. (1997). Psychoanalysis and cognitive science. A multiple code theory. New York: The Guilford Press.

Bucci, W. (2001). Pathways of emotional communication. Psychoanalytic Inquiry, 21, 40-70. 
Bucci, W. (2003). Varieties of dissociative experiences. A multiple code account and a discussion of Bromberg's case of "William". Psychoanalytic Psychology, 20, 542-557.

Carr, L., Iacoboni, M., Dubeau, M., Mazziotta, J., \& Lenzi, G. (2003). Neural mechanismsof empathy in humans: A relay from neural systems for imitation to limbic areas. Proceedings of the National Academy of Sciences, USA, 100, 5497-5502.

Davies, J. M. (1996). Linking the "pre-analytic" with the postclassical: Integration, dissociation, and the multiplicity of unconscious process. Contemporary Psycho-Analysis, 32, 553-576.

Davies, J. M. (1998). Repression and dissociation: Freud and Janet. Fairbairn's new model of unconscious process. In N. J. Skolnick and D. E. Scharff (Eds.), Fairbairn then and now. (pp. 53-69). Hillsdale, NJ: The Analytic Press, Inc.

Davies, J. M., \& Frawley, M. G. (1994). Treating the adult survivor of childhood sexual abuse. A psychoanalytic perspective. New York: Basic Books.

Doidge, N. (2007). The brain that changes itself. Stories of personal triumph from the frontiers of brain science. New York: Viking Penguin.

Dupont, J. (Ed.). (1995). The clinical diary of Sándor Ferenczi. Cambridge, MA: Harvard University Press.

Ferenczi, S. (1931). Child analysis in the analysis of adults. In M. Balint (Ed.), Final contributions to the problems and methods of psycho-analysis (pp. 126-142). London: H. Karnac (Books) Ltd.

Flax, J. (1996). Taking multiplicity seriously: Some consequences for psychoanalytic theorizing and practice. Contemporary Psycho-Analysis, 32, 577-593.

Freud, S. (1912). Recommendations to physicians practicing psycho-analysis. Standard Edition (pp. 109-120). London: Hogarth Press, 1958.

Freud, S. (1915). The unconscious. Standard Edition (pp. 159-215). London: Hogarth Press, 1958.

Gallese, V. (2001). The "shared manifold" hypothesis. Journal of Consciousness Studies, 8, 33-50.

Gallese, V. (2003). The roots of empathy: The shared manifold hypothesis and the neural basis of intersubjectivity. Psychopathology, 36, 171-180.

Gallese, V., Fadiga, L., Fogassi, L., \& Rizzolatti, G. (1996). Action recognition in the premotor cortex. Brain, 119, 593-609.

Goldberg, P. (1995). "Successful" dissociation, pseudovitality, and inauthentic use of the senses. Psychoanalytic Dialogues, 5, 493-510.

Harris, A. (1996). The conceptual power of multiplicity. Contemporary Psycho-Analysis, 32, $537-552$.

Hidas, G. (1993). Flowing over: Transference, countrertransference, telepathy. Subjective dimensions of the psychoanalytic relationship in Ferenczi's thinking. In L. Aron and A. Harris (Eds.), The legacy of Sándor Ferenczi (pp. 207-215). Hillsdale, NJ: The Analytic Press.

Klein, M. (1946). Notes on some schizoid mechanisms. In Envy and gratitude and other works 1946-1963 (pp. 1-24). London: Vintage.

Levine, H. B. (Ed.). (1990). Adult analysis and childhood sexual abuse. Hillsdale, NJ: The Analytic Press, Inc.

Lisman-Pieczanski, N. (1990). Countertransference in the analysis of an adult who was sexually abused as a child. In H. B. Levine (Ed.), Adult analysis and childhood sexual abuse (pp. 137-147). Hillsdale, NJ: The Analytic Press, Inc.

Looker, T. (1998). "Mama, why don't your feet touch the ground?" Staying with the body and the healing moment in psychoanalysis. In L. Aron and F. S. Anderson (Eds.), Relational perspectives on the body (pp. 237-262). Hillsdale, NJ: The Analytic Press, Inc.

Lyons-Ruth, K. (1998). Implicit relational knowing: Its role in development and psychoanalytic treatment. Infant Mental Health Journal, 19, 282-289.

Mitchell, S. A. (1991). Contemporary perspectives on self: Toward an integration. Psychoanalytic Dialogues, 1, 121-147.

Mitchell, S. A. (1993). Hope and dread in psychoanalysis. New York: Basic Books, pp. 95-122.

Modell, A. H. (2003). Imagination and the meaningful brain. Cambridge, MA.: The MIT Press.

Ogden, T. H. (1995). Analysing forms of aliveness and deadness of the transference- countertransference. International Journal of Psycho-Analysis, 76, 695-709. 
Pally, R. (2001). A primary role for nonverbal communication in psychoanalysis. Psychoanalytic Inquiry, 21, 71-93.

Perry, B. D. (1999). The memories of states. How the brain stores and retrieves traumatic experience. In J. M. Goodwin and R. Attias (Eds.), Splintered reflections. Images of the body in trauma (pp. 12-13). New York: Basic Books.

Pizer, S. A. (1996). The distributed self: Introduction to symposium on "The Multiplicity of Self and Analytic Technique". Contemporary Psycho-Analysis, 32, 499-507.

Pizer, S. A. (1998). Building bridges: The negotiation of paradox in psychoanalysis. Hillsdale, NJ: The Analytic Press, Inc.

Putnam, F. W. (1992). Discussion: Are alter personalities fragments or figments? Psychoanalytic Inquiry, 12, 95-111.

Reik, T. (1948). Listening wih the third ear. The inner experience of a psychoanalyst. New York: Farrar, Strauss and Giroux.

Rosenfeld, H. (1987). Listening and interpretation. Therapeutic and anti-therapeutic factors in the psychoanalytic treatment of psychotic, borderline, and neurotic patients. London: Tavistock Publications, Ltd.

Schore, A. N. (1994). Affect regulation and the origin of the self. The Neurobiology of emotional development. Hillsdale, $\mathrm{NJ}$ : Erlbaum, Inc.

Schore, A. N. (2002). Dysregulation of the right brain: A fundamental mechanism of traumatic attachment and the psychopathogenesis of posttraumatic stress disorder. Australian and New Zealand Journal of Psychiatry, 36, 9-30.

Schore, A. N. (2004). The essential role of the right brain in the implicit self: Development, pathogenesis, and psychotherapy. Implicit and Explicit Domains in Psychoanalytic Change. Association for Autonomous Psychoanalytic Institutes Conference. New York.

Shengold, L. (1989). Soul murder. The effects of childhood abuse and deprivation. New York: Random House, Inc.

Slavin, M. O. (1996). Is one self enough? Multiplicity in self-organization and the capacity to negotiate relational conflict. Contemporary Psycho-Analysis, 32, 615-625.

Slavin, M. O., \& Kriegman, D. (1992). The adaptive design of the human psyche. Psychoanalysis, evolutionary biology, and the therapeutic process. New York: The Guilford Press.

Slavin, M. O., \& Kriegman, D. (1998). Why the analyst needs to change: Toward a theory of conflict, negotiation, and mutual influence in the therapeutic process. Psychoanalytic Dialogues, 8, 247-284.

Stern, D. (1997). Unformulated experience. Hillsdale, NJ: The Analytic Press, Inc.

Stern, D. N. (1985). The interpersonal world of the infant. A view from psychoanalysis and developmental psychology. New York: Basic Books, Inc.

Stern, D. N., Sander, L. W., Nahum, J. P., Harrison, A. M., Lyons-Ruth, K., Morgan, A. C., et al. (1998). Non-interpretive mechanisms in psychoanalytic therapy: The "something more" than interpretation. The International Journal of Psycho-Analysis, 79, 903-921.

Winnicott, D. W. (1949). Mind and its relation to the psyche-soma. In Collected Papers (pp. 243-254). New York: Basic Books.

Wolf, N. S., Gales, M. E., Shane, E., \& Shane, M. (2001). The developmental trajectory from amodal perception to empathy and communication. The role of mirror neurons in this process. Psychoanalytic Inquiry, 21, 94-112.

Wrye, H. K. (1998). The embodiment of desire. Relinking the bodymind within the analytic dyad. In L. Aron and F. S. Anderson (Eds.), Relational perspectives on the body (pp. 97-116). Hillsdale, NJ: The Analytic Press, Inc. 